\title{
"Jingle" pollution problem solving path analysis Zhen Wang
}

North China Electric Power University, Baoding 071000, China

Keywords: Jingle; Resource Recover; Linkage mechanism.

\begin{abstract}
With the economic development and life rhythm speeding up, a lot of college students jingle. But at the same time, it has brought a surge in household garbage. This article is based on energy conservation and emissions reduction as the research background, to ease the take-away junk for the purpose. Based on the exploration of take-away junk in baoding city, Hebei province universities, and the conventional solution discussion, we put forward the innovative solutions, namely boxes recycling scheme. Environmental protection activities should be the multi-agent linkage, and the government, scientific research institutions, enterprises, social organizations and citizens should make joint efforts to promote the development of fast food take-away environmental protection.
\end{abstract}

\section{Analysis of the situation}

With the development of economic society and the quickening pace of life, along with the Internet growing popularity, " Jingle " presents the trend of more and more popular. And because of college students' "indoorsy", ordering takeout becomes an indispensable part of their lives.

\subsection{Existing takeout cutlery hazard is serious}

Based on the research on the production process of disposable chopsticks, they generally have the sulfur dioxide, residual hydrogen peroxide, heavy metal mercury and lead and talcum powder. The residual talcum powder and polystyrene high-temperature carcinogen dioxin on plastic boxes can follow the food entering our bodies, causing serious harm to health.

And take-out tableware is mainly made in small factories, workshops. Therefore, the existing takeout cutlery hazard is serious.

\subsection{Large amount of delivery order}

After investigation, there are about 8500 students in the second campus of NCEPU. And there are 1.164 million colleges' students in hebei province in 2014. We examined all restaurants' month delivery around the second campus of NCEPU. Find out usage of hebei college delivery month by the student number of conversion. According to the analysis of the samples, we obtain the conclusion that college students' group purchase delivery times concentrate in 2-3 times a week, and the proportion of $33.55 \%$. Followed by buying 1 times a week, the proportion is $20.94 \%$. There are $25 \%$ of students not ordering takeout. So the take-away in college students has a broad market.

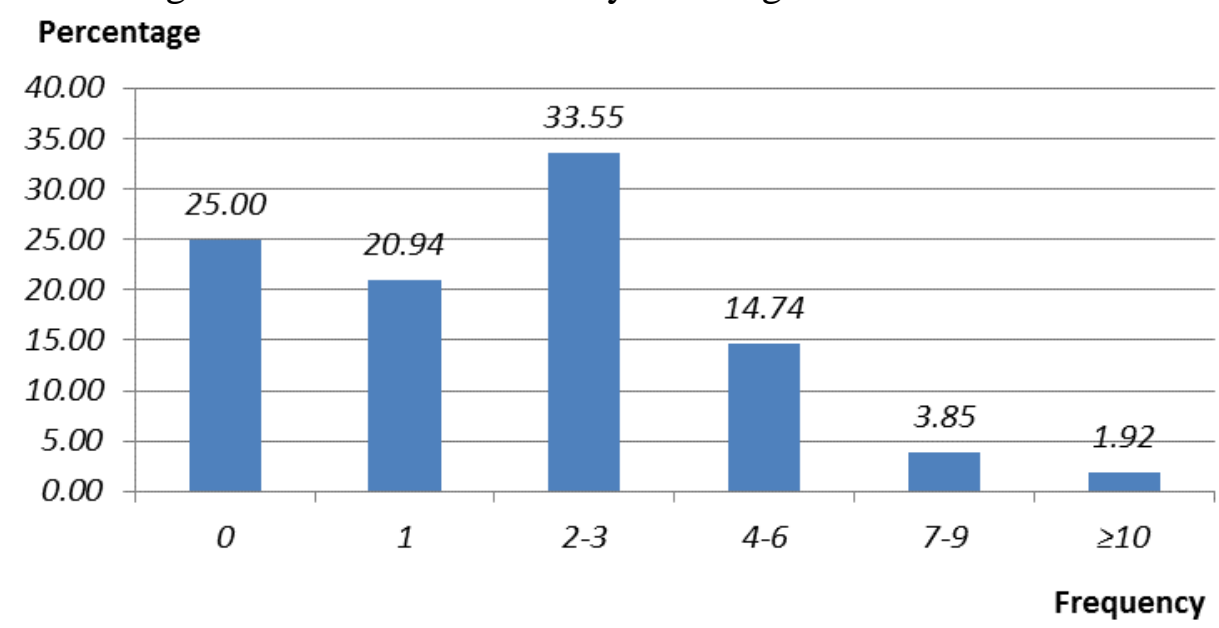

Fig.1 The times of take-out in one week 


\section{Solution design}

\subsection{Conventional solutions}

For a large number of take-away junk, some solutions exist on the market. These solutions can reduce the pollution of the take-away junk to some extent.

Biodegradable plastic lunch boxes abandoned exposing in natural for three months, the shape of the complete decomposes into pieces. It improves the environment in the vision. But its biggest flaw is that it cannot continue to degrade, not fundamentally equaling to eliminate white pollution.

For plant fiber boxes, it has good degradability and rich source of raw materials. But without removing fiber pigment, Appearance is not very desirable. It can cause water pollution.

Biological degradation boxes' main raw material is starch. Because starch is decomposed into water and carbon dioxide, and the expected blend material is also fully biodegradable materials. They not have any damage to the environment. But most of production materials is food crops, and easy to mildew.

According to the analysis on the conventional methods, they have advantages, and to a certain extent reduced the take-away garbage pollution. But its shortcoming is also very obvious. Therefore a kind of new scheme should be proposed to solve the increasingly serious take-out garbage pollution problem.

\subsection{An innovative solution}

Our solution: cleaning company is the central link. Schools, manufacturers and restaurants are implementation objects. The specific operation process: Disinfection cleaning companies regularly buy lunch boxes and chopsticks made from specific material, which are raw materials of the whole process. Through cooperation with the restaurants, or through some take-out online shopping platform, such as, eleme and other large take-out business. Tableware would be provided to them on a regular basis. The hotels also participate in the purchasing service. In addition, because the delivery of the main object are college students, so we also need schools to cooperate and support, so that the disinfection cleaning company can regularly recycling in school. In order to ensure the normal benign circulation of the entire cycle. The following is the implementation of the specific flow chart:

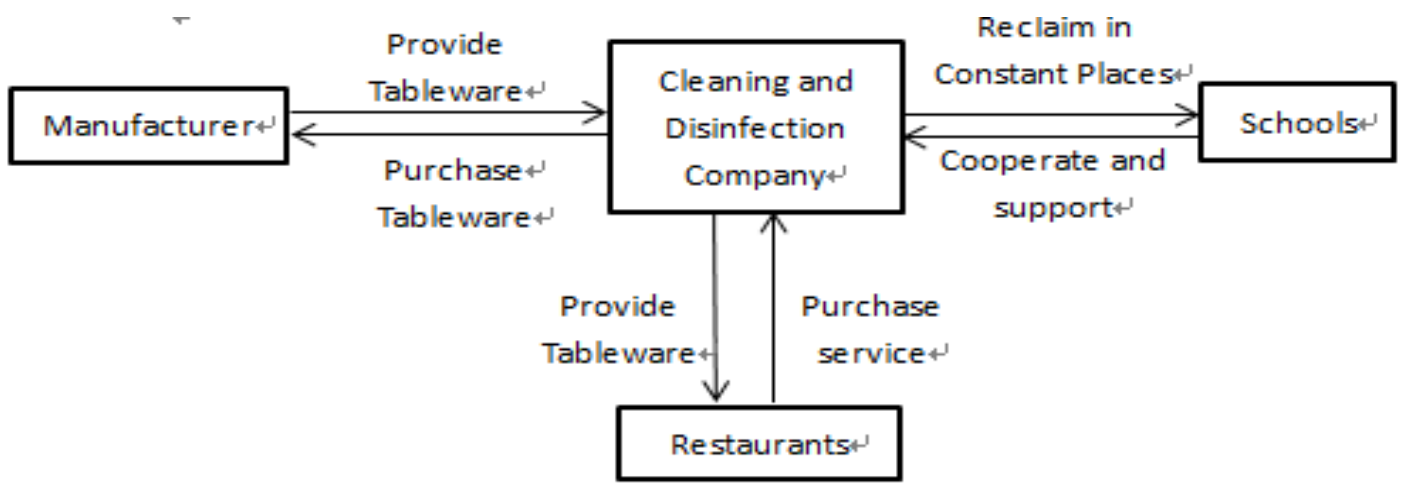

Fig.2 Implementation flow chart

The product design. The material: Polypropylene (boxes); Melamine porcelain-like (chopsticks)

The shape: The take-out is mainly divided into soup and rice class. Take-out boxes would be designed curve both round and square with rounded corners. Round lunch boxes are for soups, and square boxes are for meal.
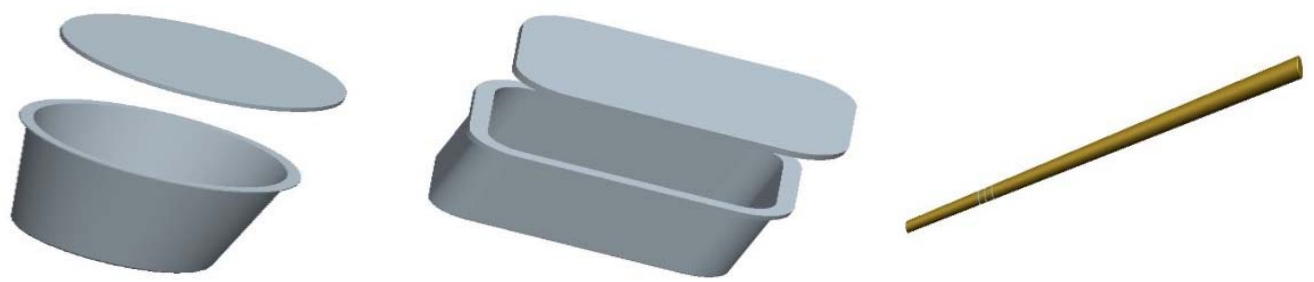

Fig. 3 Tableware design chart 
Specifications:

Arc circular: bottom diameter $26.7 \mathrm{~cm}$, height $23.7 \mathrm{~cm}$;

Square with rounded corners: length $15.5 \mathrm{~cm}$, width $10.5 \mathrm{~cm}$ and height $6.5 \mathrm{~cm}$; Chopsticks: length $22 \mathrm{~cm}$.

The features: boxes sealing good; Material of non-toxic, tasteless, in line with the

tableware of safety and health standards of the state; High temperature resistant $\left(+120{ }^{\circ} \mathrm{C}\right)$, low temperature $30{ }^{\circ} \mathrm{C}(-)$, Acid and alkali corrosion resistance, can be used to disinfect cupboard disinfected; Chopsticks of gorgeous color, fine texture, contact with your breath, feel warm and comfortable; Tableware surface smooth, easy to clean, easy to use; Using low cost.

Use fixed of year: The tableware can be used more than 300 times (about a year).

Recycling process. Disinfection cleaning company buy tableware from the producer, and then every time the restaurant will delivery take-out to customers by using these tableware, after a meal, customer will run out boxes to fixed-point recycling, then the company is responsible for recycling the tableware, and send back to the original company to clean disinfection, again after processed into the circulation and used again.

Disinfection cleaning company: (1)Buy tableware from the producer: According

to the location of the delivery week sales statistics, soup and rice take-out daily sales around NCEPU should be A and B. Considering double allowance, disinfection cleaning company should buy 2A arc round lunch box, 2B square round boxes and 2 pairs of chopsticks, $2 \mathrm{~A}+2 \mathrm{~B}$ for the entire operating system to provide the first delivery of tableware.(2)Recycle tableware from fixed-recycling point: set the take-away consumption area designated tableware recycling, after people using the cutlery, tableware can be put directly on the recycling, tableware disinfection cleaning company send the specialist to the take-away consumption of tableware recycling takeout cutlery twice a day, brings back tableware disinfection cleaning and disinfection of the company.

The restaurant: Based on their weekly sales, they buys the tableware directly from disinfection cleaning company.

The customer: Order take-out from the restaurant, after using, put the boxes on

the designated recycling point.

Designated recycling point: set the take-away consumption area designated recycling area, north China electric power university, for example, can be set in each dormitory building, the building such a recovery area.

Profit model. The following profit patterns are designed for disinfection cleaning company:

Cost of an investment, many times in return.

Pay attention to the focus and specialization.

Implementation of business outsourcing.

Form a strategic alliance.

With the help of the government's power.

\section{Complementary mechanism building}

To promote the fast food industry enterprises not only energy saving and emission reduction, but also the whole society need to work together to complete. So each subject requires collaboration, promoting takeout environmental protection, energy conservation .To solve this problem, therefore, a multiple subjects to the linkage mechanism ought to be built.

The government needs to vigorously promote the adjustment of industrial structure, strengthen the technical support the policy support. It also needs to carry out market-oriented mechanisms for energy conservation and emissions reduction, and strengthen the monitoring and early warning, supervision and inspection. Research institutions should strengthen the social responsibility, promoting the development of green technology. The body of the enterprise is to promote energy conservation and emissions reduction, each enterprise should have social sense of responsibility and sense of mission, the entrepreneur spirit, in its own economic development at the same time, to promote saving energy and reducing consumption, green ecological environment protection. To foster 
environmental social organization, let scattered through organized public way involved in the environmental protection. People should consciously to receive various forms of environmental protection publicity and education activities, choosing takeout, consciously use biodegradable, environmental protection when handling take-away junk, pay attention to the classification dustbin, active learning knowledge about environmental protection.

\section{References}

[1] Hou Yuqi NieYan. Used for disposable tableware packaging material improvement research [J]. Foreign investment in China, 2013,01:219-220.

[2] Cai Huijuan, yan han, Su Qinpo, Liu Biao, Lin Jianqing, linnane dragon, Shao Guo a. College students' usage of disposable tableware analysis [J]. Journal of henan science and technology, 2013:170.

[3] KangBingGang. Fear: disposable tableware [J]. Journal of enterprise standardization, 2005, 12:613.

[4] Li Lujing. College students' network take-away, consumption and development research [J]. Market modernization, 2015, 11:25. 